\title{
THE APRIL MEETING AT STANFORD
}

The two hundred seventy-eighth regular meeting of theSociety was held at Stanford University on Saturday, April 5, 1930. The meeting was called to order at 10:30 A.M. by President Hedrick, who, with Professor M. W. Haskell, presided over the session.

The attendance included the following twenty-five members:

Bernstein, Blichfeldt, Buck, Corbin, Engstrom, R. L. Green, M. W. Haskell, E. R. Hedrick, L. M. Hoskins, Hotelling, B. W. Jones, D. N. Lehmer, Sophia Levy, Luther, W. A. Manning, Michal, W. E. Milne, F. R. Morris, Noble, Pollock, T. M. Putnam, Pauline Sperry, Stager, Uspensky, W. M. Whyburn.

A luncheon for members and their guests was held at the Stanford Union, and later in the afternoon they were taken for a ride in the region near Palo Alto.

Titles of papers read at the meeting follow. The papers of the following authors were read by title: Basoco, E. T. Bell, Ward. The paper of Clifford Bell was read by Professor Whyburn. Mr. Debely was introduced by Professor Bernstein.

1. On certain finite sums of binomial coefficients and gamma functions, by Dr. M. A. Basoco. (Abstract No. 36-3-204-t.)

2. On Appell's decomposition of a doubly periodic function of the third kind, by Dr. M. A. Basoco. (Abstract No. 36-3205-t.)

3. A practical method for computing the modular representations of finite operations and relations, by Professor B. A. Bernstein and Mr. Nemo Debely. (Abstract No. 36-3-214.)

4. A correspondence between irregular fields, by Professor E. T. Bell. (Abstract No. 36-5-217-t.)

5. The real unit segment as a number field, by Professor E. T. Bell. (Abstract No. 36-5-218-t.)

6. Numbers of representations in certain senary quadratic forms, by Professor E. T. Bell. (Abstract No. 36-5-219-t.)

7. Analytic functions in the irregular field of all numerical functions, by Professor E. T. Bell. (Abstract No. 36-5-220-t.)

8. On a pair of simultaneous second-order differential equations, by Dr. Clifford Bell. (Abstract No. 36-3-212.) 
9. On generalizing trigonometric identities in arithmetical paraphrasing, by Dr. H. T. Engstrom (National Research Fellow). (Abstract No. 36-3-210.)

10. Certain quinary forms related to the sum of five squares, by Dr. B. W. Jones (National Research Fellow). (Abstract No. 36-3-208.)

11. An operation that generates scalar differential invariants from tensors, by Professor A. D. Michal. (Abstract No. 36-3209.)

12. The numerical determination of characteristic numbers, by Professor W. E. Milne. (Abstract No. 36-3-206.)

13. Simultaneous quadratic and linear representation, by Dr. Gordon Pall (National Research Fellow). (Abstract No. 36-3211.)

14. An apparatus for the exhibition and study of skew curves, by Mr. S. A. Pollock. (Abstract No. 36-3-207.)

15. On the reduction of the indefinite binary quadratic forms, by Professor J. V. Uspensky. (Abstract No. 36-5-221.)

16. The algebra of recurring series, by Professor Morgan Ward. (Abstract No. 36-3-215-t.)

17. Postulates for the inverse operations in a group, by Professor Morgan Ward. (Abstract No. 36-3-216-t.)

18. On systems of cyclically related differential equations, by Professor W. M. Whyburn. (Abstract No. 36-3-213.)

T. M. Putnam, Associate Secretary 